\title{
Internet addiction and associated factors among medical and allied health sciences students in northern Tanzania: a cross- sectional study
}

Innocent B. Mboya ${ }^{1,2,3^{*}}$ (D), Beatrice John Leyaro ${ }^{1}$, Alberto Kongo ${ }^{2}$, Charles Mkombe ${ }^{2}$, Eliah Kyando ${ }^{2}$ and Johnston George ${ }^{2}$

\begin{abstract}
Background: Internet addiction is one of the fast-growing addictive behaviors and is a significant public health problem affecting a large number of people worldwide. Excessive use of the internet among university students increases their risk of internet addiction and related negative consequences. This study aimed to determine the prevalence and factors associated with internet addiction among medical and allied health sciences students in northern Tanzania.

Methods: This cross-sectional study was conducted at Kilimanjaro Christian Medical University College (KCMUCo) from May to June 2018. A total of 500 consenting undergraduate students were sampled using the Simple Random Sampling technique proportional to the size of each class and a self-administered questionnaire used to collect data. Internet addiction was measured using a 20-item internet addiction test (IAT-20). Generalized linear model with Poisson family and log link function was used to estimate prevalence ratio (PR) and the corresponding 95\% confidence intervals for factors associated with internet addiction.
\end{abstract}

Results: The prevalence of internet addiction was 31\%. Undergraduate students using the internet at the college were less likely to be addicted to internet ( $P R=0.45,95 \% \mathrm{Cl} 0.23,0.86, p=0.02$ ) compared to those using both at the hostel/ home and college. Higher prevalence of internet addiction was among those who used internet for a long time, i.e., $5 \mathrm{~h}$ or more per day $(\mathrm{PR}=1.84,95 \% \mathrm{Cl} 1.30,2.63, p=0.001)$ and for social networking $(\mathrm{PR}=1.64,95 \% \mathrm{Cl} 1.17,2.31, p=$ 0.004) compared to those who used for less than $5 \mathrm{~h}$ per day and academic purposes, respectively.

(Continued on next page)

\footnotetext{
* Correspondence: ib.mboya@gmail.com

${ }^{1}$ Department of Epidemiology and Biostatistics, Institute of Public Health,

Kilimanjaro Christian Medical University College, P. O. Box 2240, Moshi,

Tanzania

${ }^{2}$ Department of Community Health, Institute of Public Health, Kilimanjaro

Christian Medical University College, P. O. Box 2240, Moshi, Tanzania

Full list of author information is available at the end of the article
}

(C) The Author(s). 2020 Open Access This article is licensed under a Creative Commons Attribution 4.0 International License, which permits use, sharing, adaptation, distribution and reproduction in any medium or format, as long as you give appropriate credit to the original author(s) and the source, provide a link to the Creative Commons licence, and indicate if changes were made. The images or other third party material in this article are included in the article's Creative Commons. licence, unless indicated otherwise in a credit line to the material. If material is not included in the article's Creative Commons licence and your intended use is not permitted by statutory regulation or exceeds the permitted use, you will need to obtain permission directly from the copyright holder. To view a copy of this licence, visit http://creativecommons.org/licenses/by/4.0/ The Creative Commons Public Domain Dedication waiver (http://creativecommons.org/publicdomain/zero/1.0/) applies to the data made available in this article, unless otherwise stated in a credit line to the data. 


\begin{abstract}
(Continued from previous page)
Conclusions: Thirty-one percent of undergraduate students in northern Tanzania were addicted to the internet. Internet addiction was associated with using the internet at the college, a long time using the internet per day, and social networking. The college administration should put effort into improving the accessibility, reliability, and regulation of college internet services to promote learning and academic productivity. We also recommend awareness creation intervention about the harmful consequences of excessive internet use in this population. More studies are needed to determine the burden of mental, psychological, and social problems associated with internet addiction in high-risk populations, and associated consequences.
\end{abstract}

Keywords: Prevalence, Internet addiction, Internet addiction test, University students, Tanzania

\section{Background}

Internet addiction is one of the fast-growing addictive behavior and is a significant public health problem, affecting a large number of people worldwide [1]. Repeated use of the internet leads to excessive use, usually termed as internet addiction or problematic internet use [2-6]. Internet addiction is a psychological dependence on the internet characterized by salience/excessive use, withdrawal, tolerance, negative repercussions/conflict, craving, and mood modification $[1,7,8]$. The use of the internet among students in universities and colleges has grown considerably [8-10]. Internet addiction among university/college students increases the risk of negative mental, physical, social, and financial consequences $[1$, 11, 12]. These include suicide, depression, psychological distress (depressive symptoms), anxiety, aggression, poor academic performance, cognitive impairment, poor dietary habits, lack of sleep, visual and hearing impairment, social isolation, and substance abuse such as cigarette smoking and alcohol use [2, 4, 11, 13-18]. The physical health consequences also include thromboembolism, musculoskeletal, ophthalmic, and metabolic problems [11]. These problems are likely to have devastating consequences to the wellbeing of students across universities in Tanzania, which may have a long-term impact on the social and economic welfare of the country.

The global burden of internet addiction among university students has not been established. However, studies in the USA have shown that $5-12 \%$ of students from different colleges have problematic internet use $[4,19]$. In Asian countries, the prevalence ranged between $3.7 \%$ in India [20] to $37 \%$ in Malaysia and Iraq $[9,10]$ while in African countries, the prevalence ranged between 5.1\% in Mauritius [21] to $16.8 \%$ in Kenya [22]. While the accessibility and use of the internet are high among university students in Tanzania [23], the burden of internet addiction is also not known.

Availability and use of the internet among university students are crucial in their academic endeavors [2]. However, other than academic activities, excessive gaming, internet-based gambling, sexual internet-based pre-occupations (such as viewing pornography), developing and sustaining intimate online relationships, entertainment and socializing or social networking through different social media platforms increase the odds of problematic internet use/ internet addiction [1, 2, 5, 9, 21]. Off-campus residence, longer time spent on the internet, frequency of internet use, and lower grade point average also have a significant influence on internet addiction in this population $[4,14,16,24]$. There is conflicting evidence on the differences in internet addiction among male compared to female students $[5,17$, 20-22, 25] though the former (males) are considered most at risk. In Tanzania, it is also unclear what factors increase the risk of internet addiction among university students, which have high access to internet services. The interplay of demographic, behavioral, social and academic factors may intensify the internet addiction problem and associated consequences in the student population.

Policies to limit accessibility, protect vulnerable individuals, internet addiction counseling, and addiction supervision centers have been established in some countries [1]. Tanzania has the national information and communications technologies policy in place that provides for legal and regulatory frameworks for the accessibility and use of the internet [26]. Current evidence is, therefore, crucial for informed policy decisions and for designing interventions to address problems associated with excessive use of the internet, especially among high-risk groups. This study aimed to determine the prevalence and factors associated with internet addiction among university students in northern Tanzania. On top of establishing the burden of internet addiction in this population, findings from this study may contribute to awareness creation on the associated risk factors and consequences, hence encourage students to take precautionary measures. Also, these findings may inform specific interventions by respective or other Universities/ colleges to promote better learning experiences among their students and inform the public health interventions to improve mental health and wellbeing in the country. 


\section{Methods}

\section{Study design and setting}

We carried out a cross-sectional study between May and June 2018 at Kilimanjaro Christian Medical University College (KCMUCo) located in Moshi Municipality, Kilimanjaro region in North-eastern Tanzania. KCMU Co is among the four universities in Moshi Municipality, northern Tanzania, and is the only university in the region offering medical education and other allied health programs. Programs offered in this higher learning institution include Diploma and Bachelor's in health laboratories, Bachelor in Nursing, Diploma in Occupation Therapy, Diploma and Bachelor in Physiotherapy, Diploma and Bachelor in Prosthetics and Orthotics, Doctor of Medicine, Bachelor in Optometry and Diploma in HIV and AIDS care. The college had about 1600 undergraduate students between the year 2018-2019.

\section{Study population, sample size, and sampling technique} The study population and inclusion criteria were the registered undergraduate medical and allied health sciences students at KCMUCo who were in class during the data collection period and provided their informed consent. We used a single proportion formula for sample size calculation using a standard normal value of 1.96 at $95 \%$ confidence interval, 3.5\% margin of error, and $16.8 \%$ prevalence of internet addiction among university students in Kenya [22]. After adding $10 \%$ of non-response, a minimum required sample size was 500 students. We applied a simple random sampling technique using probability proportional to the size of each class to sample students from their respective classes.

\section{Study variables}

The dependent variable in this study was internet addiction, assessed using the Internet Addiction Test (IAT-20) score. This tool is a 20-item 5-point Likert scale self-reporting tool used to assess internet addiction and its severity. This tool has been validated and used in other parts of the world [7, 14, 19, 27], but has not been validated in Tanzania. We calculated the IAT score by adding the scores obtained for all 20 items, with a total ranging from 0 to 100 [17]. After computing scores for each question, we categorized internet addiction into a binary variable whereby those with a score of 50 and above were considered addicted to the internet and not addicted if otherwise. The independent variables included socio-demographical characteristics, particularly age in years, year of study, sex, marital status, and area of residence. Internet use practices included gadgets for internet use (college computers, personal/ own device or a combination of these two), method of internet access (College Wi-Fi, mobile data/ personal hotspot, or both), amount of money in Tanzania shillings spent on mobile data in a typical day, a regular place for internet use (hostel/ home, college, or both), time in hours spent using internet per day, and primary purpose using the internet (academic/ social networking and surfing).

\section{Data collection methods, tools, and procedures}

A self-administered questionnaire was used for data collection. The questionnaire collected information on participant social-demographic characteristics, internet use practices, the purpose of internet use, and the Internet Addiction Test. The questionnaire was in English, an official language at higher learning institutions in Tanzania. Trained medical students at KCMUCo (third to fifth authors) collected data. Data collectors visited students in their respective classes and clearly explained the purpose of the study. After addressing all questions related to this study, students were handled over the questionnaire and asked to respond in about 15-20 min. Data collectors were available to ensure that participants respond to questions themselves (given that they were in class with fellow students) and also clarified any raised concerns. Finally, data collectors thanked respondents for their time and cooperation. All completed questionnaires were then collected and revised for completeness.

\section{Statistical analysis}

We performed data cleaning and analysis using Stata version 15.1. Categorical variables were summarized using frequency and percentages, while the median and interquartile range used to summarize numeric variables. Using Cronbach's Alpha statistic, we assessed the reliability of the IAT-20 items. Generalized linear model with Poisson family and log link function was used to estimate prevalence ratio (PR) and the corresponding 95\% confidence intervals for factors associated with internet addiction. We developed several adjusted analyses models to determine factors independently associated with internet addiction using stepwise regression. The pairwise correlation assessed the collinearity between variables included in the analysis. We used the likelihood ratio test to evaluate the effect of either retaining or removing age and sex in the multivariable analysis being the known confounders. A mode without these variables was considered the best fit.

\section{Results}

\section{Characteristics of study participants}

The mean age of 500 respondents was 23.8, with a standard deviation of 2.4 years, and about three quarters were aged $\leq 24$ years. More than half $(58.4 \%)$ of all respondents were males, and $60 \%$ were from the doctor of medicine program. Only $6.2 \%$ were in union/ married, $89.2 \%$ resided off-campus, and over $92.2 \%$ were beneficiaries of the Higher Education Student Loans Board 
(HESLB), with only three receiving private sponsorship (Table 1).

\section{Internet use practices}

Seventy percent of all respondents access the internet using personal devices, i.e., mobile phones, laptops, and tablets. Half (51\%) access the internet using both own devices and college computers. The median amount of money spent on mobile data in a typical day was 500 Tanzanian shillings, equivalent to 0.22USD [given 1 USD $=2300$ Tanzanian Shillings], and more than half (56.4\%) spent $\leq 500$ Tshs per day. Sixty percent of all respondents regularly use the internet both at hostels/ home and the college. The median time (IQR) spent on the internet on a typical day was $5(3,8)$ hours, and $44.8 \%$ spent $<5 \mathrm{~h}$ a day. Academic reasons (56.4\%) were

Table 1 Characteristics of study participants $(N=500)$

\begin{tabular}{|c|c|c|}
\hline Variables & Frequency & Percentage \\
\hline \multicolumn{3}{|l|}{ Age in years } \\
\hline Mean (SD) & $23.8(2.4)$ & \\
\hline$\leq 24$ & 365 & 73.0 \\
\hline$>24$ & 135 & 27.0 \\
\hline \multicolumn{3}{|l|}{ Sex } \\
\hline Male & 292 & 58.4 \\
\hline Female & 208 & 41.6 \\
\hline \multicolumn{3}{|l|}{ Program of study } \\
\hline Doctor of medicine & 298 & 59.6 \\
\hline Nursing & 90 & 18.0 \\
\hline Laboratory science & 51 & 10.2 \\
\hline Physiotherapy & 35 & 7.0 \\
\hline Optometry & 12 & 2.4 \\
\hline Prosthetics and orthotics & 14 & 2.8 \\
\hline \multicolumn{3}{|l|}{ Year of study } \\
\hline Year 2 & 144 & 28.0 \\
\hline Year 3 & 216 & 43.0 \\
\hline Year 4 & 87 & 17.4 \\
\hline Year 5 & 53 & 10.6 \\
\hline \multicolumn{3}{|l|}{ Marital status } \\
\hline In union & 31 & 6.2 \\
\hline Not in union & 469 & 93.8 \\
\hline \multicolumn{3}{|l|}{ Residence } \\
\hline On-campus & 54 & 10.8 \\
\hline Off-campus & 446 & 89.2 \\
\hline \multicolumn{3}{|l|}{ Source of fund } \\
\hline Family/personal & 39 & 7.8 \\
\hline HESLB/Sponsor & 461 & 92.2 \\
\hline
\end{tabular}

the primary purpose of internet use in this population (Table 2).

\section{Prevalence of internet addiction}

The median internet addiction score was 38 and interquartile range of 26-53. The Cronbach's alpha test for the reliability of the 20 items used to measure internet addition provided a scale of $91.1 \%$, indicating the test is reliable. The overall prevalence of internet addiction among 500 undergraduate students was $31 \%$.

\section{Unadjusted analysis for factors associated with internet addiction}

Factors associated with internet addiction in the unadjusted analysis were the place for internet use, time spent using the internet per day, and primary purpose for internet use (Table 3). The prevalence of internet addiction was $14.3 \%$ among students using the internet through college premises, $40.2 \%$ among those spending $\geq 5 \mathrm{~h}$ on the internet per day, and $44.5 \%$ among those who used the internet for social networking. Prevalence was significantly lower ( $\mathrm{PR}=0.40,95 \% \mathrm{CI} 0.21,0.77, p=$ 0.01) among those using the internet at the college

Table 2 Internet use practices $(N=500)$

\begin{tabular}{|c|c|c|}
\hline Internet use practices & Frequency & Percentage \\
\hline \multicolumn{3}{|l|}{ Gadget for internet use } \\
\hline College computers & 8 & 1.6 \\
\hline Personal/Own device & 351 & 70.2 \\
\hline Mixed & 141 & 28.2 \\
\hline \multicolumn{3}{|l|}{ Method of internet access } \\
\hline College Wi-Fi alone & 15 & 3.0 \\
\hline Mobile data/personal hotspot & 230 & 46.0 \\
\hline All the above & 255 & 51.0 \\
\hline \multicolumn{3}{|c|}{ Amount (Tshs) spent using mobile data in a day } \\
\hline Median (IQR) & $500(500,1000)$ & \\
\hline$\leq 500$ & 282 & 56.4 \\
\hline$>500$ & 218 & 43.6 \\
\hline \multicolumn{3}{|l|}{ Commonplace of internet use } \\
\hline Hostel/home & 133 & 26.6 \\
\hline College & 70 & 14.0 \\
\hline Both hostel/home and college & 297 & 59.4 \\
\hline \multicolumn{3}{|c|}{ Time (hours) spent using the internet per day } \\
\hline Median (IQR) & $5(3,8)$ & \\
\hline$<5$ & 224 & 44.8 \\
\hline$\geq 5$ & 276 & 55.2 \\
\hline \multicolumn{3}{|c|}{ The primary purpose of internet use } \\
\hline Academic & 282 & 56.4 \\
\hline Social networking & 155 & 31.0 \\
\hline Internet surfing & 63 & 12.6 \\
\hline
\end{tabular}


Table 3 Unadjusted analysis for factors associated with internet addiction ( $N=500)$

\begin{tabular}{|c|c|c|c|c|}
\hline Variables & $n$ & $\begin{array}{l}\text { Addicted } \\
\text { Yes (\%) }\end{array}$ & $\mathrm{CPR}^{\mathbf{a}}(95 \% \mathrm{Cl})$ & $P$-value \\
\hline \multicolumn{5}{|l|}{ Age (years) } \\
\hline$\leq 24$ & 365 & $116(31.8)$ & $1.10(0.77,1.58)$ & 0.61 \\
\hline$>24$ & 135 & 39 (28.9) & 1.00 & \\
\hline \multicolumn{5}{|l|}{ Sex } \\
\hline Male & 292 & $100(34.2)$ & 1.00 & \\
\hline Female & 208 & $55(26.4)$ & $0.77(0.56,1.07)$ & 0.12 \\
\hline \multicolumn{5}{|l|}{ Year of study } \\
\hline Year 2 & 144 & $41(28.5)$ & 1.00 & \\
\hline Year 3 & 216 & $75(34.7)$ & $1.22(0.83,1.78)$ & 0.31 \\
\hline Year 4 & 87 & $20(23.0)$ & $0.81(0.47,1.38)$ & 0.43 \\
\hline Year 5 & 53 & $19(35.8)$ & $1.26(0.73,2.17)$ & 0.41 \\
\hline \multicolumn{5}{|l|}{ Marital status } \\
\hline In union & 31 & $7(22.6)$ & $0.72(0.34,1.53)$ & 0.39 \\
\hline Not in union & 469 & $148(31.6)$ & 1.00 & \\
\hline \multicolumn{5}{|l|}{ Residence } \\
\hline On-campus & 54 & $18(33.3)$ & 1.00 & \\
\hline Off-campus & 446 & $137(30.7)$ & $0.92(0.56,1.51)$ & 0.74 \\
\hline \multicolumn{5}{|l|}{ Source of fund } \\
\hline Family/personal & 39 & $9(23.1)$ & 1.00 & \\
\hline HESLB/Sponsor & 461 & $146(31.7)$ & $1.37(0.70,2.69)$ & 0.36 \\
\hline \multicolumn{5}{|l|}{ Gadget for internet use } \\
\hline College computers & 8 & $1(12.5)$ & $0.43(0.06,3.13)$ & 0.40 \\
\hline Personal device & 351 & $113(32.2)$ & $1.11(0.77,1.58)$ & 0.58 \\
\hline Mixed & 141 & $41(29.1)$ & 1.00 & \\
\hline \multicolumn{5}{|l|}{ Method of internet access } \\
\hline College Wi-Fi alone & 16 & $2(12.5)$ & $0.43(0.11,1.74)$ & 0.24 \\
\hline Mobile data/personal hotspot & 230 & $79(34.3)$ & $1.18(0.86,1.62)$ & 0.31 \\
\hline All the above & 254 & $74(29.1)$ & 1.00 & \\
\hline \multicolumn{5}{|l|}{ Commonplace of internet use } \\
\hline Hostel/home & 133 & $39(29.3)$ & $0.82(0.57,1.19)$ & 0.29 \\
\hline College & 70 & $10(14.3)$ & $0.40(0.21,0.77)$ & 0.01 \\
\hline Both hostel/home and college & 297 & $106(35.7)$ & 1.00 & \\
\hline \multicolumn{5}{|c|}{ Amount (Tshs) spent using mobile data in a day } \\
\hline$\leq 500$ & 282 & $85(30.1)$ & 1.00 & \\
\hline$>500$ & 218 & $70(32.1)$ & $1.07(0.78,1.46)$ & 0.70 \\
\hline \multicolumn{5}{|c|}{ Time (hours) spent using the internet per day } \\
\hline$<5$ & 224 & 44 (19.6) & 1.00 & \\
\hline$\geq 5$ & 276 & $111(40.2)$ & $2.05(1.44,2.90)$ & $<0.001$ \\
\hline \multicolumn{5}{|l|}{ Primary purpose for internet use } \\
\hline Academic & 282 & $67(23.8)$ & & \\
\hline Social networking & 155 & $69(44.5)$ & $1.87(1.34,2.62)$ & $<0.001$ \\
\hline Internet surfing & 63 & $19(30.2)$ & $1.27(0.76,2.11)$ & 0.36 \\
\hline
\end{tabular}

${ }^{a}$ Crude prevalence ratio 
compared to those using both at the hostel/home and college. In contrast, those who used the internet for a long time, i.e., $5 \mathrm{~h}$ or more per day were more likely to have internet addiction $(\mathrm{PR}=2.05,95 \% \mathrm{CI} 1.44,2.90, p<$ 0.001) compared to those used for less than $5 \mathrm{~h}$ per day. Also, a higher prevalence of internet addiction was among those using the internet for social networking $(\mathrm{PR}=1.87,95 \% \mathrm{CI} 1.34,2.62, p<0.001)$ compared to those used for academic purposes.

\section{Adjusted analysis for factors associated with internet addiction}

In multivariable analysis, factors that remained to be significantly $(p<0.05)$ associated with internet addiction were commonplace for internet use, average time spent using the internet per day and primary purpose for internet use. Undergraduate students using the internet at the college were less likely to have internet addiction $(\mathrm{PR}=0.45,95 \% \mathrm{CI} 0.23,0.86, p=0.02)$ compared to those who used both at the hostel/home and college. Higher prevalence of internet addiction was among students who used internet for a long time, i.e., $5 \mathrm{~h}$ or more per day $(\mathrm{PR}=1.84,95 \% \mathrm{CI} 1.30,2.63, p=0.001)$ and for social networking $(\mathrm{PR}=1.64,95 \% \mathrm{CI} 1.17,2.31, p=0.004)$ compared to those used for less than $5 \mathrm{~h}$ per day and for academic purposes (Table 4).

\section{Discussion}

In this study, the prevalence of internet addiction was $31 \%$. Internet addiction was significantly associated with using internet at the college, spending $5 \mathrm{~h}$ or more using the internet per day, and using the internet for social networking. The prevalence of internet addiction in this study was higher than that reported from the USA [4, 19], Asia [20], and among African countries [21, 22]. A

Table 4 Adjusted analysis for factors associated with internet addiction $(N=500)$

\begin{tabular}{llll}
\hline Variable & $\mathrm{APR}^{\mathbf{a}}$ & $95 \% \mathrm{Cl}$ & $\boldsymbol{P}$-value \\
\hline Regular place for internet use & & & \\
Hostel/home & 0.82 & $(0.57,1.18)$ & 0.28 \\
College & 0.45 & $(0.23,0.86)$ & 0.02 \\
$\quad$ Both hostel/home and college & 1.00 & & \\
Time (hours) spent using the internet per day & & \\
$<5$ & 1.00 & & 0.001 \\
$\geq 5$ & 1.84 & $(1.30,2.63)$ & \\
Primary purpose for internet use & & & 0.004 \\
Academic & 1.00 & $(1.17,2.31)$ & 0.59 \\
Social networking & 1.64 & $(0.69,1.92)$ & \\
Internet surfing & 1.15 & & \\
\hline
\end{tabular}

${ }^{a}$ Adjusted prevalence ratio, adjusted for a regular place for internet use, average time spent using the internet per day and primary purpose for internet use slightly higher prevalence (37\%) was reported in Malaysia and Iraq $[9,10]$ as well as $(40.7 \%)$ in Iran [27]. Variations in prevalence could be due to differences in the tools used. For instance, a study in Iraq [10] utilized an 8-item scale as opposed to the 20-item scale used in this study. In contrast, [16, 21] utilized a modified version of the scale, and [5] used a different tool (i.e., Chen Internet Addiction Scale) to assess internet addiction. Higher prevalence may also be attributed to internet access using personal devices, considering that more than $70 \%$ of all respondents in this study accessed the internet using their mobile devices.

The higher prevalence of IA in this study may have serious implications for both social, mental, and physical health as well as financial consequences. The combined effect of these problems could have serious implications for academic performance [2, 16, 28, 29]. For example, problems with self-care, difficulty in performing daily routine, pain and discomfort, anxiety, and depression were the consequences of internet addiction reported among young Vietnamese population (15-25 years of age) comprising a mixture of high school and university students [18]. Other literature reported consistent findings, which also included additional critical mental, physical, and social problems associated with internet addiction among university students $[1,3,4,9,11,15$, $17,22,24]$. Internet addiction problems should, therefore, be addressed both as a public health and clinical problem focusing on reducing potential negative psychosocial consequences of risky/ harmful content, excessive/ maladaptive use, and financial burden [11], particularly on the high-risk populations. Mental health research in Tanzania is limited. We recommend more studies to assess the potential risk factors, consequences, and costeffective as well as context-specific interventions to address the common mental health problems in the country, such as the alarming prevalence of internet addiction.

In this study, university students spending a long time (more than $5 \mathrm{~h}$ per day) on the internet increased the likelihood of internet addiction, which is consistent with findings from other studies [14, 16, 21, 24]. An excessive amount of time spent on the internet serves as a distraction from schoolwork. This situation puts students at a disadvantage in as far as academic productivity is involved [16]. If used positively, the internet is potentially useful and informative both academically and socioeconomically, and it is capable of assisting university students to achieve their lifetime goals [2, 22].

University students who reported using the internet for social networking were more likely to be addicted to the internet compared to those who used it for academic purposes. This finding concurs with other studies [2, 9, $16,17,21,22,30]$. Like in other studies, the most 
commonly used social media platforms in this population included Instagram, YouTube, Snapchat, Skype, WhatsApp, and Facebook, among others [2, 30, 31]. These students could, therefore, be spending less time online engaging in academic activities, which are likely to affect their academic productivity or performance [2, $16,28]$, which increases the risk of mental, psychosocial and physical consequences.

University students who were using the internet at the college were less likely to have internet addiction compared to those using the internet both at home/ hostel and college. In India, university students who stayed in rented accommodations were more likely to be addicted to the internet [14]. Internet use through the college facilities might offer some protection against excessive use, by restricting the contents to academic-related materials. Concerted efforts by the college should ensure the availability, reliability, and regulation of college internet services to encourage learning and enhance academic performance, particularly on the campus premises.

While the current study has provided an overview of the current status of the burden of internet addiction among university students in Tanzania, it has several limitations. Firstly, this study used a cross-sectional design that does not allow drawing any inference on the cause-effect relationship of internet addiction and associated factors. Secondly, the study might have missed students who were severely addicted to the internet as they are more likely to miss classes. The tool utilized for data collection is a self-reported measure to assess internet addiction; hence is subject to potential information bias, particularly recall and self-desirability bias. Also, this tool has not been validated in the Tanzanian context, highlighting a need for a validation study. Lastly, these findings may not be generalized to students in other universities or the general population across the country.

\section{Conclusions}

Thirty-one percent of medical and allied health sciences students in northern Tanzania were addicted to the internet. Internet addiction was associated with using the internet at the college, spending more time using the internet per day, and using the internet for social networking. The college administration should put effort into improving the accessibility, reliability, and regulation of college internet services that may promote learning, and academic productivity. We also recommend awareness creation intervention about the harmful consequences of excessive internet use in this population. More studies are needed to determine the burden of mental, psychological, and social problems associated with internet addiction in high-risk populations, and associated consequences. Furthermore, to inform policy decisions and interventions, there is a need to intensify research studies on mental health issues in Tanzania.

\section{Abbreviations}

IAT: Internet Addiction Test; KCMUCo: Kilimanjaro Christian Medical University College; PR: Prevalence ratio

\section{Acknowledgments \\ This study was carried out as part of a Doctor of Medicine Training by three undergraduate students (including the third author) at Kilimanjaro Christian Medical University College. We want to acknowledge all undergraduate students who consented and took part in this study whose information made this study possible.}

\section{Authors' contributions}

Conceptualization; IBM, EK, CM, and AK. Data curation; IBM, EK, CM, and AK Formal analysis; IBM. Investigation; EK, CM, and AK. Methodology; IBM, EK, CM, and AK. Project administration, Supervision, \& Validation; IBM, JG, BJL. Visualization; IBM. Roles/Writing - original draft - IBM; Writing - review \& editing - IBM, BJL, and JG. The author(s) read and approved the final manuscript.

\section{Funding}

The authors received no specific funding for the design of the study and collection, analysis, and interpretation of data and in writing the manuscript.

\section{Availability of data and materials}

The datasets generated and/ or analyzed during the current study are available in the Mendeley Data repository, https://doi.org/10.17632/ 8thfmxwmm4.1.

\section{Ethics approval and consent to participate}

Ethical approval was obtained from the Kilimanjaro Christian Medical University College Research Ethics and Review Committee (KCMU-CRERC). Written informed consent was sought from all study participants before the interviews. Confidentiality and privacy were maintained by using unique identification numbers instead of names.

\section{Consent for publication}

Not applicable.

\section{Competing interests}

The authors declare that they have no competing interests.

\section{Author details}

${ }^{1}$ Department of Epidemiology and Biostatistics, Institute of Public Health, Kilimanjaro Christian Medical University College, P. O. Box 2240, Moshi, Tanzania. ${ }^{2}$ Department of Community Health, Institute of Public Health Kilimanjaro Christian Medical University College, P. O. Box 2240, Moshi, Tanzania. ${ }^{3}$ School of Mathematics, Statistics \& Computer Science, University of KwaZulu Natal, Pietermaritzburg, Private Bag X01, Scottsville 3209, South Africa.

Received: 12 March 2020 Accepted: 29 June 2020

Published online: 09 July 2020

\section{References}

1. WHO. Public health implications of excessive use of the internet, computers, smartphones and similar electronic devices: meeting report, Main Meeting Hall, Foundation for Promotion of Cancer Research, National Cancer Research Centre, Tokyo, Japan, 27-29 August 2014. Geneva: World Health Organization; 2015.

2. Islam S, Malik MI, Hussain S, Thursamy R, Shujahat M, Sajjad M. Motives of excessive internet use and its impact on the academic performance of business students in Pakistan. J Subst Abus. 2018;23(1):103-11.

3. Kuss JD, Griffiths MD, Karila L, Billieux J. Internet addiction: a systematic review of epidemiological research for the last decade. Curr Pharm Des. 2014;20(25):4026-52. 
4. Derbyshire KL, Lust KA, Schreiber LRN, Odlaug BL, Christenson GA, Golden DJ, Grant JE. Problematic internet use and associated risks in a college sample. Compr Psychiatry. 2013;54(5):415-22.

5. Salehi M, Khalili MN, Hojjat SK, Salehi M, Danesh A. Prevalence of internet addiction and associated factors among medical students from Mashhad, Iran in 2013. Iran Red Crescent Med J. 2014;16(5):e17256.

6. Thatcher A, Goolam S. Defining the south African internet 'addict': prevalence and biographical profiling of problematic internet users in South Africa. S Afr J Psychol. 2005;35(4):766-92.

7. Mercy ON, Oluwatosin BO. Internet addiction among undergraduates in University of Ibadan: imperative for counselling intervention. Afr J Psychol Stud Soc Issues. 2015;18(3):1-14.

8. Kandell JJ. Internet addiction on campus: the vulnerability of college students. Cyberpsychol Behav. 1998;1(1):11-7.

9. Ching SM, Hamidin A, Vasudevan R, Sazlyna M, Wan Aliaa W, Foo YL, Yee A, Hoo F. Prevalence and factors associated with internet addiction among medical students-a cross-sectional study in Malaysia. Med J Malaysia. 2017;72(1):7.

10. Babakr ZH, Majeed K, Mohamedamin P, Kakamad K. Internet addiction in Kurdistan university students: prevalence and association with self-control. Eur J Educ Res. 2019;8(3):867-73.

11. Lee S-Y, Kim MS, Lee HK. Prevention strategies and interventions for internet use disorders due to addictive behaviors based on an integrative conceptual model. Curr Addict Rep. 2019;6(3):303-12

12. Cash $H$, Rae CD, Steel AH, Winkler A. Internet addiction: a brief summary of research and practice. Curr Psychiatr Rev. 2012;8(4):292-8.

13. Mei S, Gao T, Li J, Zhang Y, Chai J, Wang L, Zhang Z, Zhang H. Internet addiction in college students and its relationship with cigarette smoking and alcohol use in Northeast China. Asia Pac Psychiatry. 2017;9(4). https:// doi.org/10.1111/appy.12281.

14. Anand N, Jain PA, Prabhu S, Thomas C, Bhat A, Prathyusha P, Bhat SU, Young $\mathrm{K}$, Cherian AV. Internet use patterns, internet addiction, and psychological distress among engineering university students: a study from India. Indian J Psychol Med. 2018;40(5):458.

15. Missaoui SG, Brahim T, Bouriga W, Abdelaziz AB. Prevalence and consequences of internet addiction in a cohort of Tunisian adolescents: a pilot study. J Child Adolesc Behav. 2015:3:2375-4494

16. Salubi OG, Nekhwevha F, Oyediran-Tidings S, Ondari-Okemwa E. Digital media usage and prevalence of internet addiction among undergraduate students in South Africa. Int J Web Appl. 2019;10(4):127-36.

17. Upadhayay N, Guragain S. Internet use and its addiction level in medical students. Adv Med Educ Pract. 2017;8:641-7.

18. Tran BX, Hinh ND, Nguyen LH, Le BN, Nong VM, Thuc VTM, Tho TD, Latkin C, Zhang MW, Ho RC. A study on the influence of internet addiction and online interpersonal influences on health-related quality of life in young Vietnamese. BMC Public Health. 2017;17(1):138.

19. Jelenchick LA, Becker T, Moreno MA. Assessing the psychometric properties of the internet addiction test (IAT) in US college students. Psychiatry Res. 2012;196(2-3):296-301.

20. Patil SD, Deshmukh JS, Dagdiya KR. Prevalence and pattern of internet addiction among medical students in Nagpur, Maharashtra. Int J Community Med Public Health. 2017:4:2412-6.

21. Smita G, Azhar F. Prevalence and characteristics of internet addiction among university students in Mauritius. SM J Case Rep. 2018;4(1):1077.

22. Maroma FO, Karega M, Oteyo JS. Relationship between depression and pathological internet use among university students. Cypriot J Educ Sci. 2019;14(2):201-7.

23. Kipapy SS, Ndeke SDFN, Stephen A. Internet use among university students in Iringa region, Tanzania: trends, threats and mitigation. Int J Indian Psychol. 2018;6(3):201-14.

24. Orsal O, Orsal O, Unsal A, Ozalp SS. Evaluation of internet addiction and depression among university students. Procedia Soc Behav Sci. 2013;82:445-54

25. Shao Y-J, Zheng T, Wang Y-Q, Liu L, Chen Y, Yao Y-S. Internet addiction detection rate among college students in the People's Republic of China: a meta-analysis. Child Adolesc Psychiatry Ment Health. 2018;12(1):25.

26. MoCT. National information and communications technologies policy: Ministry of Communications and Transport. Dar es Salaam: United Republic of Tanzania; 2003.

27. Bahrainian SA, Alizadeh KH, Raeisoon MR, Gorji OH, Khazaee A. Relationship of internet addiction with self-esteem and depression in university students. J Prev Med Hyg. 2014;55(3):86-9.
28. Bhushan S, Piplani S, Tekkalaki BV. Internet addiction and performance of health science students. Int J Community Med Public Health. 2018;5(9):3824

29. Xin M, Xing J, Pengfei W, Houru L, Mengcheng W, Hong Z. Online activities, prevalence of internet addiction and risk factors related to family and school among adolescents in China. Addict Behav Rep. 2018;7:14-8.

30. Kumar A, Nawaz AS, Kumar R, Yamuna B. Internet addiction and factors associated with it: a cross sectional study among students of a medical college in Davangere, Karnataka. Int J Community Med Public Health. 2017; 4(7):2525.

31. Martin F, Wang C, Petty T, Wang W, Wilkins P. Middle school students' social media use. J Educ Technol Soc. 2018;21(1):213-24.

\section{Publisher's Note}

Springer Nature remains neutral with regard to jurisdictional claims in published maps and institutional affiliations.
Ready to submit your research? Choose BMC and benefit from:

- fast, convenient online submission

- thorough peer review by experienced researchers in your field

- rapid publication on acceptance

- support for research data, including large and complex data types

- gold Open Access which fosters wider collaboration and increased citations

- maximum visibility for your research: over $100 \mathrm{M}$ website views per year

At BMC, research is always in progress.

Learn more biomedcentral.com/submissions 